\title{
Calculation of SS, TN and TP Specific Concentration Factors for Land-Use Types Using a Simple Watershed Model
}

\author{
Seiko Yoshikawa ${ }^{1}$, Donglai Ma ${ }^{1,3}$, Tadamasa Saito ${ }^{1,4}$, Kenji Matsumori ${ }^{1}$, Yuko Itoh $^{2}$, Kazunori Kohyama $^{1} \&$ \\ Masahiro Kobayashi ${ }^{2}$ \\ ${ }^{1}$ National Agriculture and Food Research Organization, Tsukuba, Japan \\ ${ }^{2}$ Forestry and Forest Products Research Institute, Tsukuba, Japan \\ ${ }^{3}$ Graduate school of Systems and Information Engineering, University of Tsukuba, Japan \\ ${ }^{4}$ College of Agruculture, Ibaraki University, Inashiki-gun, Ibaraki, Japan \\ Correspondence: Seiko Yoshikawa, National Agriculture and Food Research Organization, 3-1-3 Kannon-dai, \\ Tsukuba, Ibaraki 305-8604, Japan. Tel: 81-029-838-8326. E-mail: seikoyo@affrc.go.jp
}

Received: June 10, 2019

Accepted: September 2, 2019

Online Published: September 29, 2019

doi:10.5539/jsd.v12n5p138

URL: https://doi.org/10.5539/jsd.v12n5p138

\begin{abstract}
To contribute to the prediction of rainfall-related disasters, specific concentration factors that indicate the suspended solid (SS), total nitrogen (TN), and total phosphorus (TP) load intensities to river water for each land-use type were calculated using a simple watershed land-use model across Japan by applying the following multiple regression equation, according to the land-use ratios and published SS, TN and TP data.

$$
\mathrm{C}=\sum_{i=1}^{4} a_{i} x_{i}
$$

$C$ : $\mathrm{SS}, \mathrm{TN}$ and TP concentrations $\left(\mathrm{mg} \mathrm{L}^{-1}\right) ; a_{i}: \mathrm{SS}, \mathrm{TN}$ and TP specific concentration factor for land use $i$; $x_{i}$ : ratio of land use $i$; land use: 1 paddy fields, 2 upland fields, 3 forests, 4 urban areas.

The land-use ratios for watersheds, whose lower ends were observation points of river water quality, were determined by the GIS technique using a published database of DEM and LULC mesh data. The SS specific concentration factor was 15.4 (from a 95\% lower limit value of 12.0 to a $95 \%$ upper limit value of 18.8 ), 11.5 (7.4 to 15.6), 3.9 (2.6 to 5.1), and 11.2 (9.2 to 13.2) for paddy fields, upland fields, forests and urban areas, respectively $(\mathrm{n}=5103)$. The TN specific concentration factor was 1.67 (from a 95\% lower limit value of 1.34 to a 95\% upper limit value of 2.01), 4.08 (3.64 to 4.51), 0.76 (0.67 to 0.90 ), and 3.57 (3.38 to 3.76) for paddy fields, upland fields, forests and urban areas, respectively $(\mathrm{n}=3256)$. The TP specific concentration factor was 0.146 (from a 95\% lower limit value of 0.119 to a 95\% upper limit value of 0.172 ), 0.172 (0.138 to 0.206$), 0.044$ ( 0.033 to 0.055$)$, and 0.267 (0.253 to 0.282 ) for paddy fields, upland fields, forests and urban areas, respectively $(n=3256)$. These specific concentration factors had regional tendencies, such as suburban or rural, intensive or extensive agriculture, and so on.
\end{abstract}

Keywords: watershed land-use model, SS, TN, TP, specific concentration factor

\section{Introduction}

Increased nitrate in drinking water, and the eutrophication process by which a body of water becomes enriched in dissolved nutrients that stimulate the growth of aquatic plant life usually resulting in the depletion of dissolved oxygen are all major environmental issues (Cooper 1993; Kumazawa 2002; Nagumo et al. 2004). Therefore, the quantification of nutrient loads from both non-point sources and point sources becomes important. An increasing proportion of cropland area in drainage basins has been found to be strongly correlated with the nitrogen concentration of river water (Yoshikawa et al. 2015; Tabuchi et al. 1995; Woli et al. 2004; Mochizuki et al. 2013) Hojito et al. (2003) estimated the nitrogen loading and nitrogen concentration in discharged water for each prefecture by assuming that surplus nitrogen in cropland soil will readily dissolve in water percolating through the soil. They considered not only fertilizer and manure nitrogen and absorbed nitrogen by crops but also nitrogen in rainfall, nitrogen fixation, nitrogen deposition and denitrification. However, they did not consider 
nitrogen discharge from forests and urban areas, and they did not verify the accuracy of the estimated nitrogen concentrations.

We previously developed a simple model to estimate nutrient concentrations of river water based on the land-use ratios of watersheds and evaluated the impacts of land-use type on the total nitrogen (TN) and total phosphorus (TP) in river water, and the $\mathrm{NO}_{3}-\mathrm{N}$ concentration in shallow groundwater in Kagawa Prefecture. (Mochizuki et.al.. 2013; Yoshikawa et al. 2015). According to the results, the TN and TP impacts from croplands to river water, and the $\mathrm{NO}_{3}-\mathrm{N}$ impact from croplands to shallow groundwater were approximately half and more than half, respectively. Surplus nitrogen (nitrogen applied as fertilizer and manure - nitrogen absorbed by crops) correlated with the $\mathrm{TN}$ concentration of river water and the $\mathrm{NO}_{3}-\mathrm{N}$ concentration of shallow groundwater.

In recent years, sediment (suspended solid)-related disasters have increased due to the intensification and localization of rainfall events caused by climate change (Japan Meteorological Agency 2019, Tokio Marine Nichido 2013). Some parts of Nitrogen (N) and phosphorus (P) are discharged with suspended solid (SS) loads. The SS, TN and TP runoff concentrations are dependent on land use and land cover, conservative measures, topography, climate conditions (primarily rainfall), and so on. Among these, land use and land cover are expected to be the predominant contributing factors in normal climate conditions. Thus, to contribute to the prediction of rainfall-related disasters in the future, SS, TN, and TP specific concentration factors that indicate the SS, TN and TP load intensities to rivers from each land-use type in normal climate conditions are calculated across Japan using a simple watershed land-use model.

\section{Materials and Methods}

\subsection{Study Area and Watershed Delineation and Land-Use Ratio Determination}

There are approximately 8,000 observation points of river water quality across Japan (Ministry of Environment). The land-use ratios for watersheds, whose lower ends are observation points of river water quality, were determined using the technique of a Geographic Information System (GIS) (Arc GIS, ESRI Ltd. Redland, California, U.S.A.) from a published database of DEM (GSI, 10B, raster data) and LULC mesh data (JAXA, ALOS AVNIR-2, 10-m mesh data, 2006-2011). The classification categories of ALOS AVNIR-2 were \#0: not classified, \#1: water, \#2: urban areas, \#3: paddy fields, \#4: upland fields, \#5: pastures, \#6: deciduous broad-leaved trees, \#7: deciduous needle-leaved trees, \#8: evergreen broad-leaved trees, \#9: evergreen needle-leaved trees, \#10: bare soil, \#11: snow and ice, \#253: other, and \#255: no data. Classification category \#3 was defined as "paddy fields", the cumulative total of \#4 and \#5 was defined as "upland fields", the cumulative total of \#6, \#7, \#8, and \#9 was defined as "forests", and \#2 was defined as "urban areas". Study areas are watersheds whose ends are observation points of river water quality across Japan.

\subsection{Estimation of TN, TP, and SS Specific Concentration Factors for Each Land-Use Type}

We employed a simple watershed land-use model (Mochizuki et al. 2013; Yoshikawa et al. 2015) to estimate the SS, TN and TP specific concentration factors for each land-use type. In the model, parameter $a_{i}$ is a specific concentration factor for land-use type $i$. The SS, TN and TP concentrations were assumed to be composed of the contribution of the four land-use types of upland fields, paddy fields, forests and urban areas, having respective specific concentration factors. The following equation (1) was used to calculate the SS, TN and TP specific concentration factors:

$$
\mathrm{C}=\sum_{i=1}^{4} a_{i} x_{i}
$$

where $C$ is the SS, TN and TP concentration of the river water, $a_{i}$ is the SS, TN, and TP specific concentration for land-use type $i$, reflecting the magnitude of the $i$ land-use contribution to SS, TN, and TP in the river water, and $x_{i}$ is the land-use ratio for the land-use type $i$.

The $a_{i}$ was estimated as a partial regression coefficient for the multiple regression analysis of the SS, TN and TP concentrations at the end of watersheds and the land-use ratios of the watersheds. The SS, TN and TP concentrations were the averaged value of all measurements from 2000 to 2009 (Ministry of Environment).

\section{Results}

\subsection{Delineated Watersheds}

The determined watersheds numbered approximately 6,000 (Fig. 1). Some watershed areas overlapped because there were one or more observation points for each river. Approximately 2,000 watersheds distributed across predominantly plane areas could not be delineated because of DEM resolution limitations. 


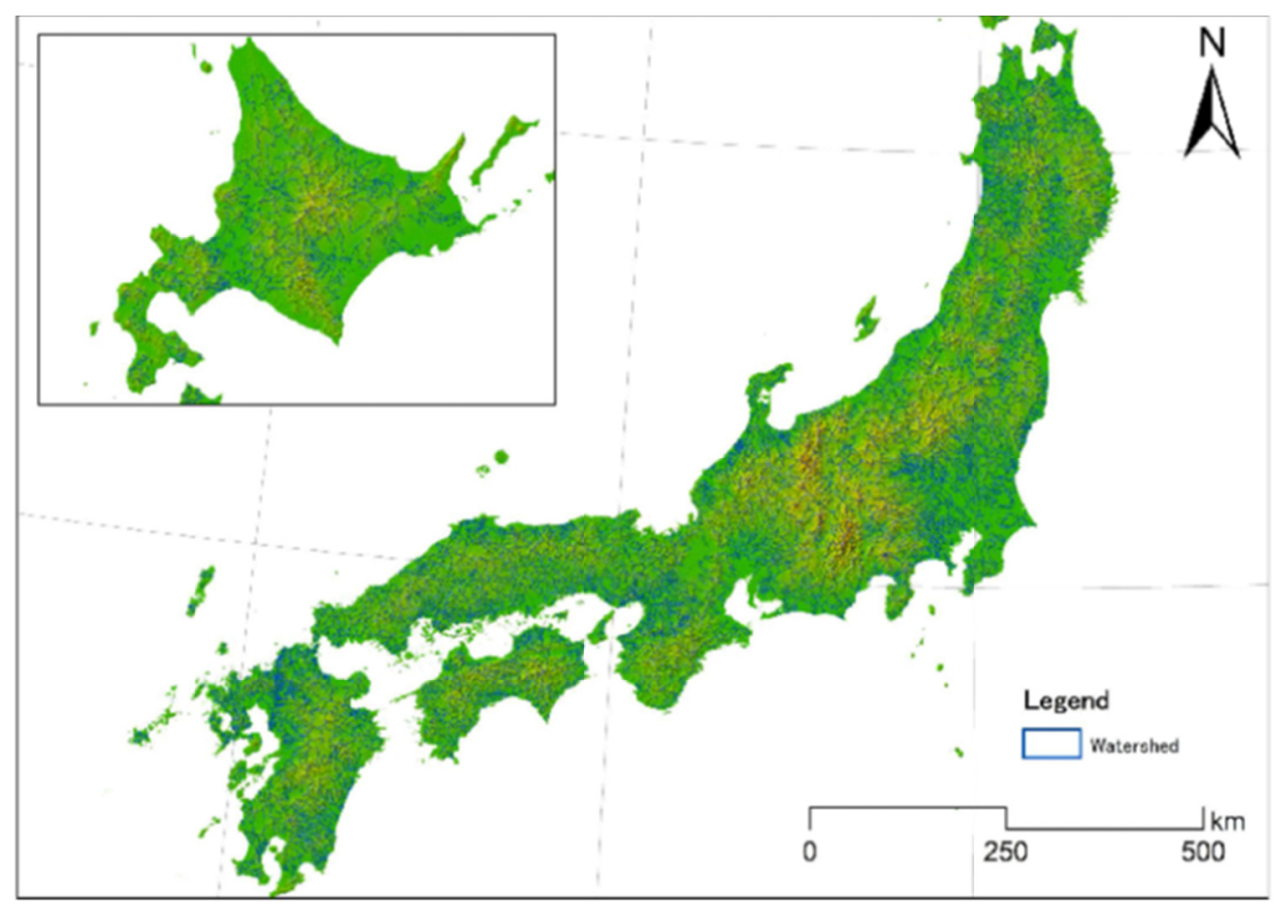

Figure 1. Delineated watersheds whose ends are observation points of river-water quality

\subsection{SS Concentration Distribution and SS Specific Concentration Factors for Each Land Use}

Fig. 2 depicts the SS concentrations at the ends of watersheds. The SS concentrations were relatively high in the western part of Kyusyu, in the Hokuriku region, and the western part of Hokkaido. There were 5,103 delineated watersheds with river water quality observation points that included SS data for all 10 years. For all watersheds, the SS specific concentration factors were calculated according to equation (1). The calculated results for the SS specific concentration factor were 15.4 (from a 95\% lower limit value of 12.0 to a $95 \%$ upper limit value of 18.8 ), 11.5 (7.4 to 15.6), 3.9 (2.6 to 5.1), and 11.2 (9.2 to 13.2) for paddy fields, upland fields, forests and urban areas, respectively. 


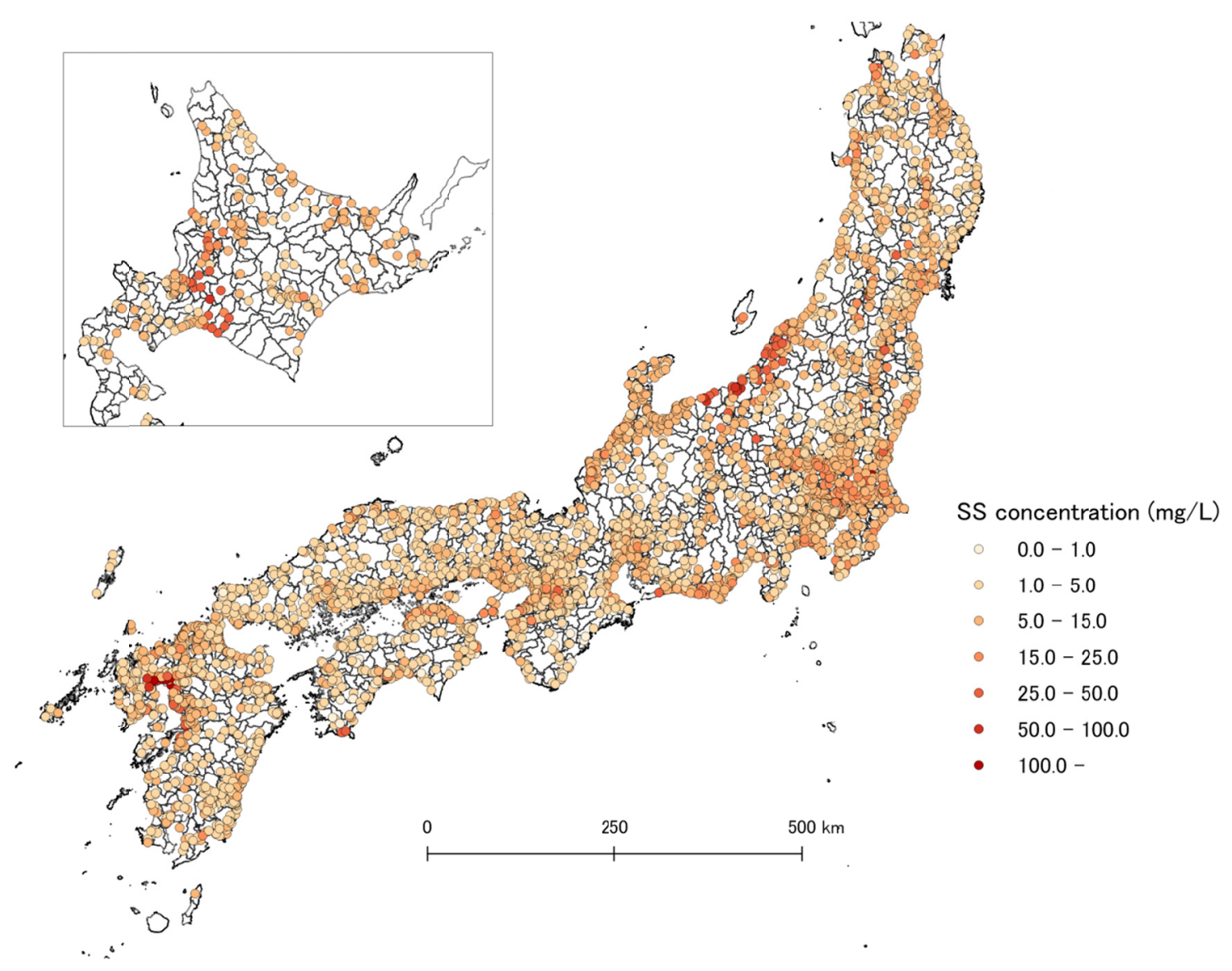

Figure 2. SS concentrations at the ends of watersheds

The calculated SS specific concentration factors by prefecture are depicted in Fig. 3 for each land-use type. Unconfident values $(\mathrm{p}>0.1)$ are not shown. The SS concentrations of the observation points were analyzed in relation to the geological types of the observation points (Fig. 4) as shown in Fig. 5. Although the results are greatly dispersed, sandy materials or course materials might be vulnerable to SS runoff. However, the geological features of entire watersheds should be investigated for detailed analysis, instead of only analyzing the data from a single observation point. 

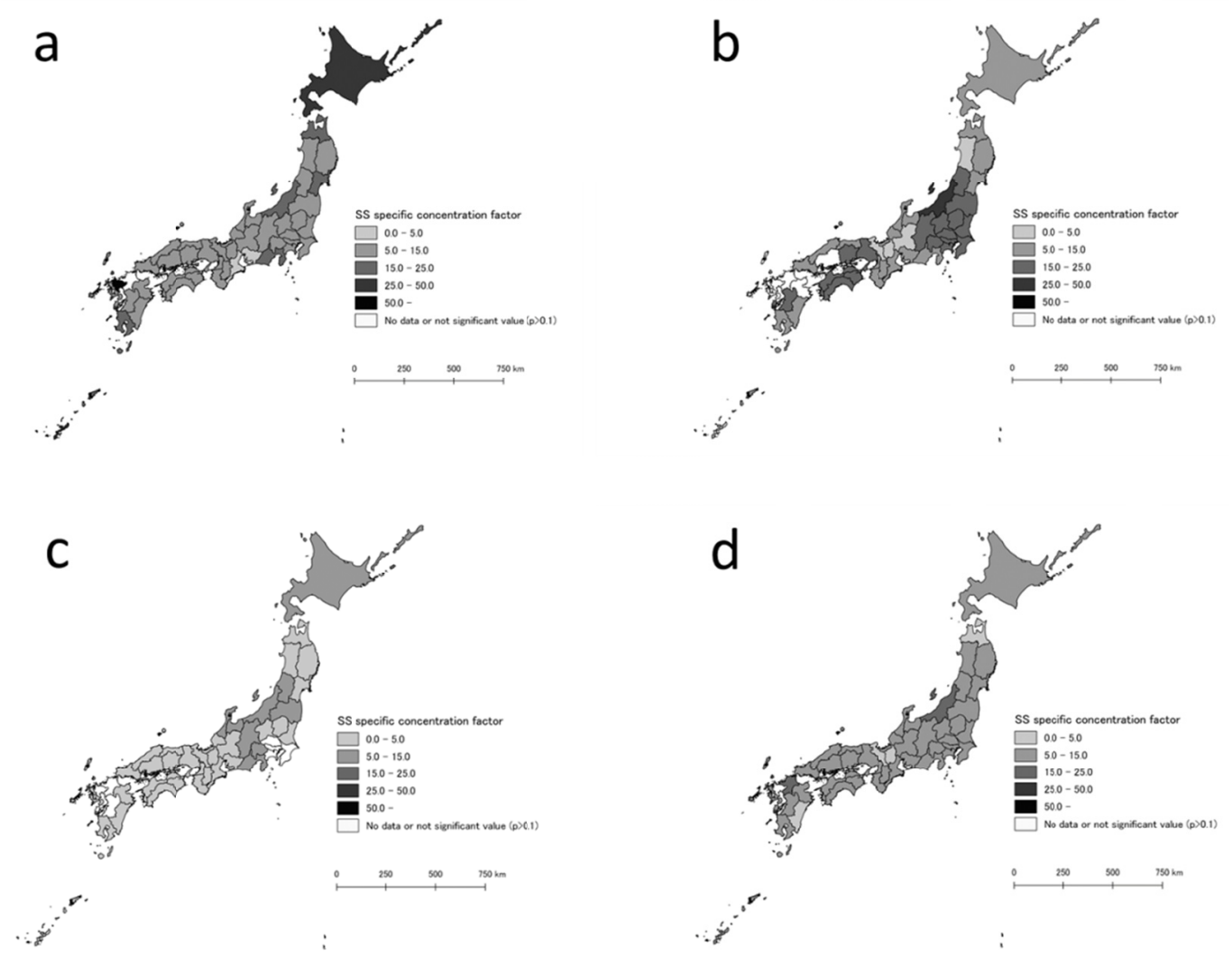

Figure 3. SS specific concentration factors for a:paddy fields, b:upland fields, c:forests, d; urban areas calculated by prefectures or regions. (Unconfident values $(>0.1)$ are not described.)

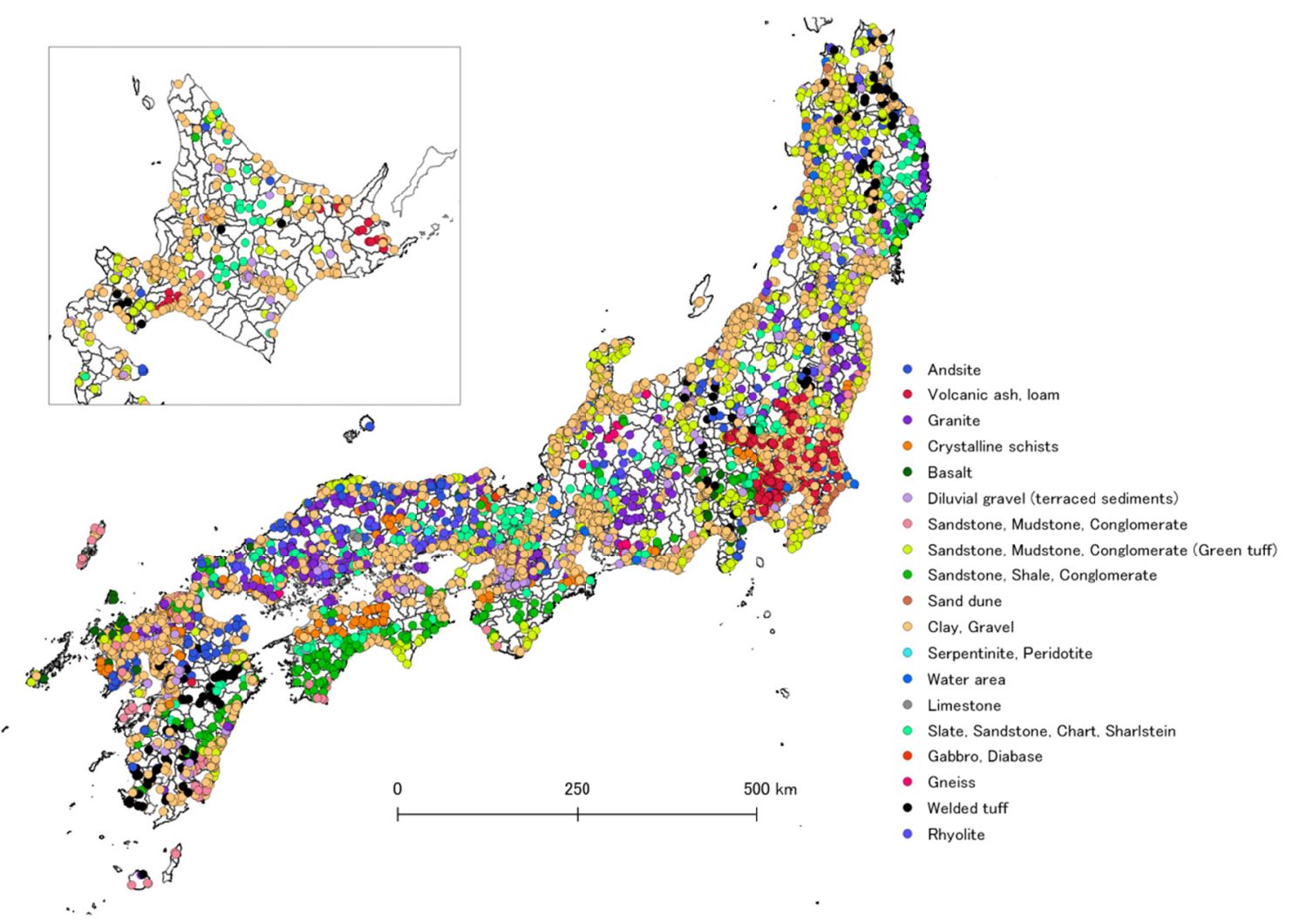

Figure 4. Geological types of the observation points of river-water quality 


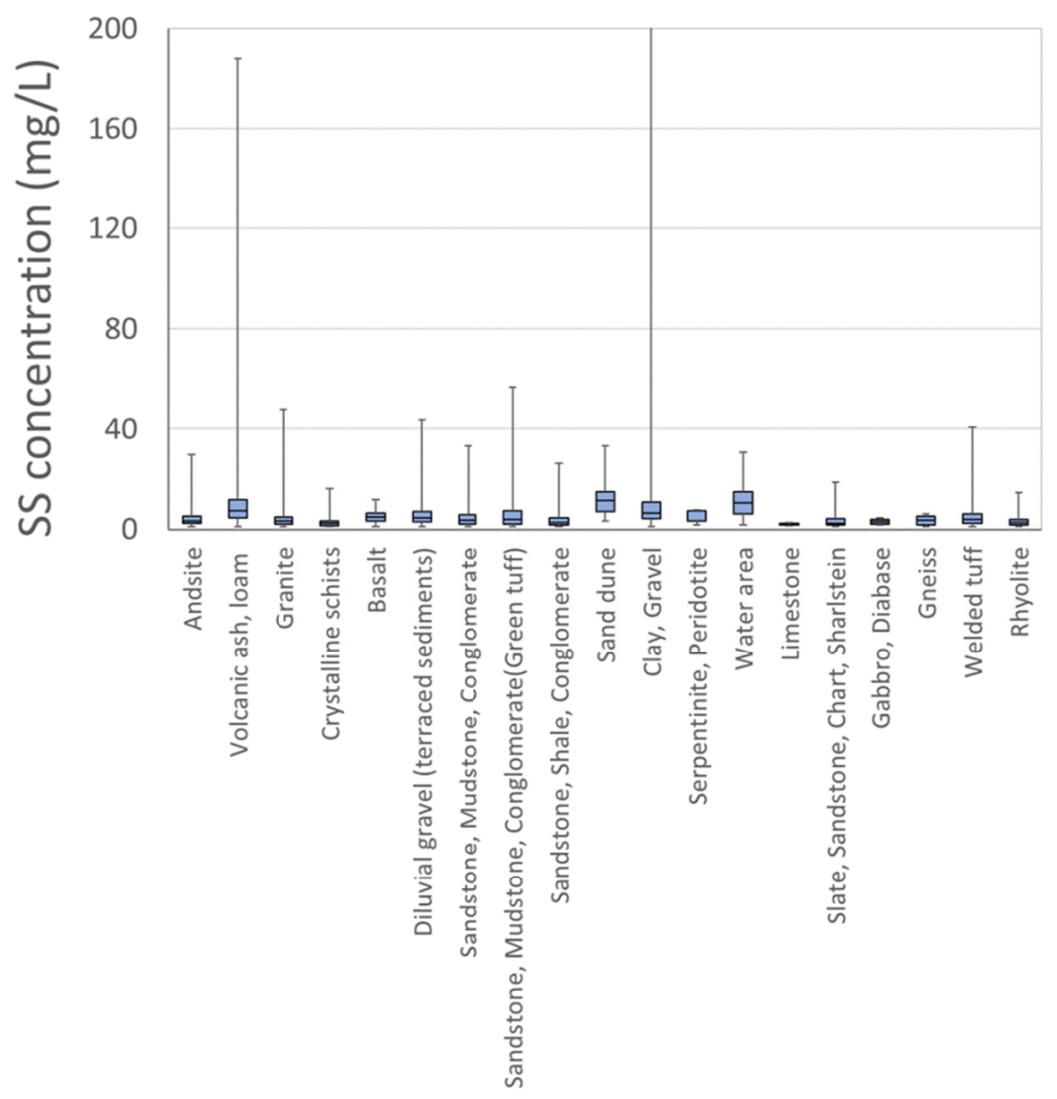

Figure 5. SS concentrations by geological types

\subsection{TN Concentration Distribution and TN Specific Concentration Factors for Each Land-Use Type}

The TN concentrations at the ends of watersheds are depicted in Fig. 6. There were 3,256 delineated watersheds with observation points that included TN data for all 10 years. The TN concentrations were relatively high in large urban areas such as Tokyo and its suburbs, Osaka and its suburbs, and Fukuoka and its suburban areas. The calculated TN specific concentration factors by prefecture are shown in Fig. 7 for each land-use type. Unconfident values ( $>0.1)$ are not shown. The TN specific concentration factor was 1.67 (from a $95 \%$ lower limit value of 1.34 to a $95 \%$ upper limit value of 2.01 ), 4.08 (3.64 to 4.51$), 0.76$ (0.67 to 0.90 ), and 3.57 (3.38 to 3.76) for paddy fields, upland fields, forests and urban areas, respectively. 


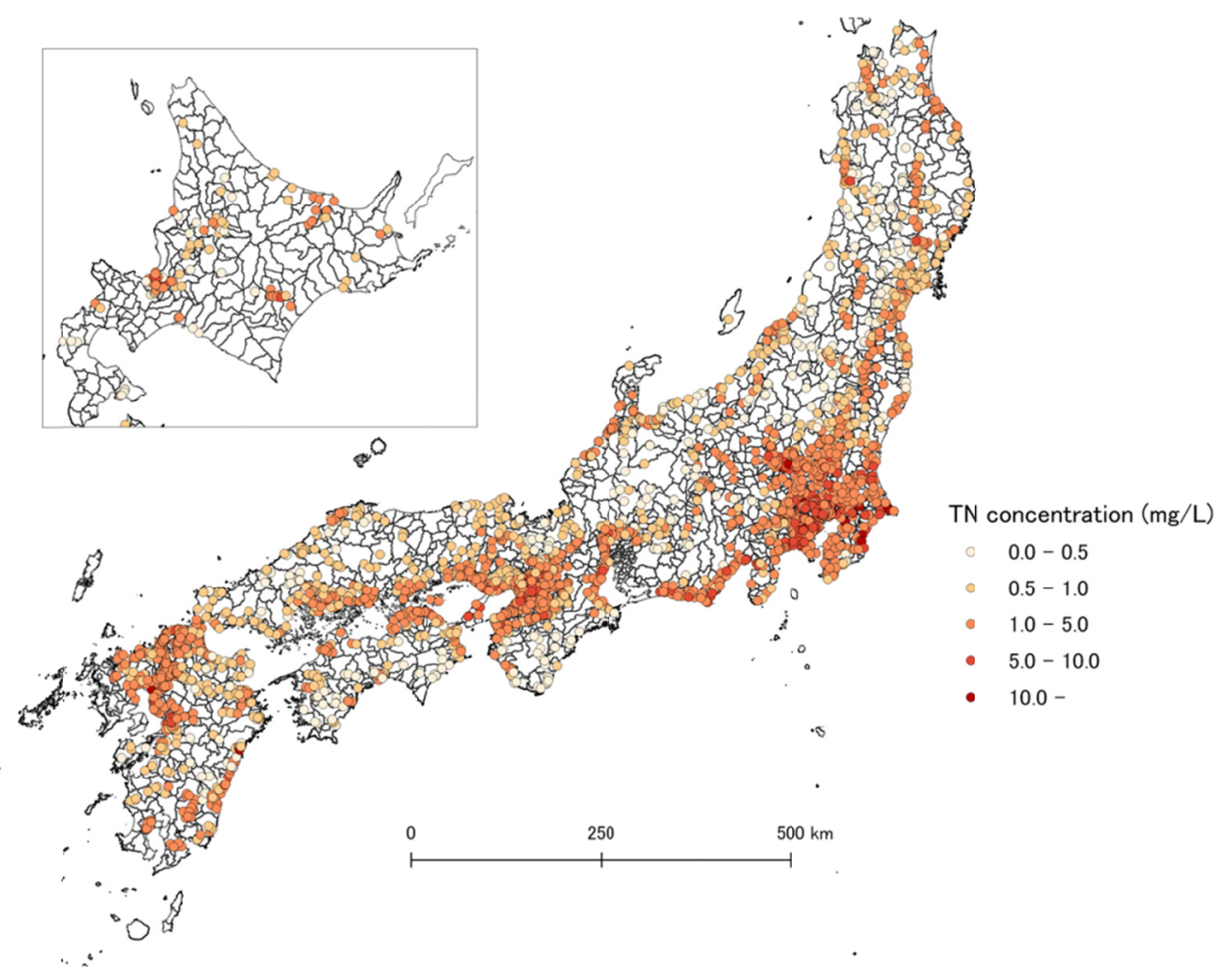

Figure 6. TN concentrations at the end of watersheds
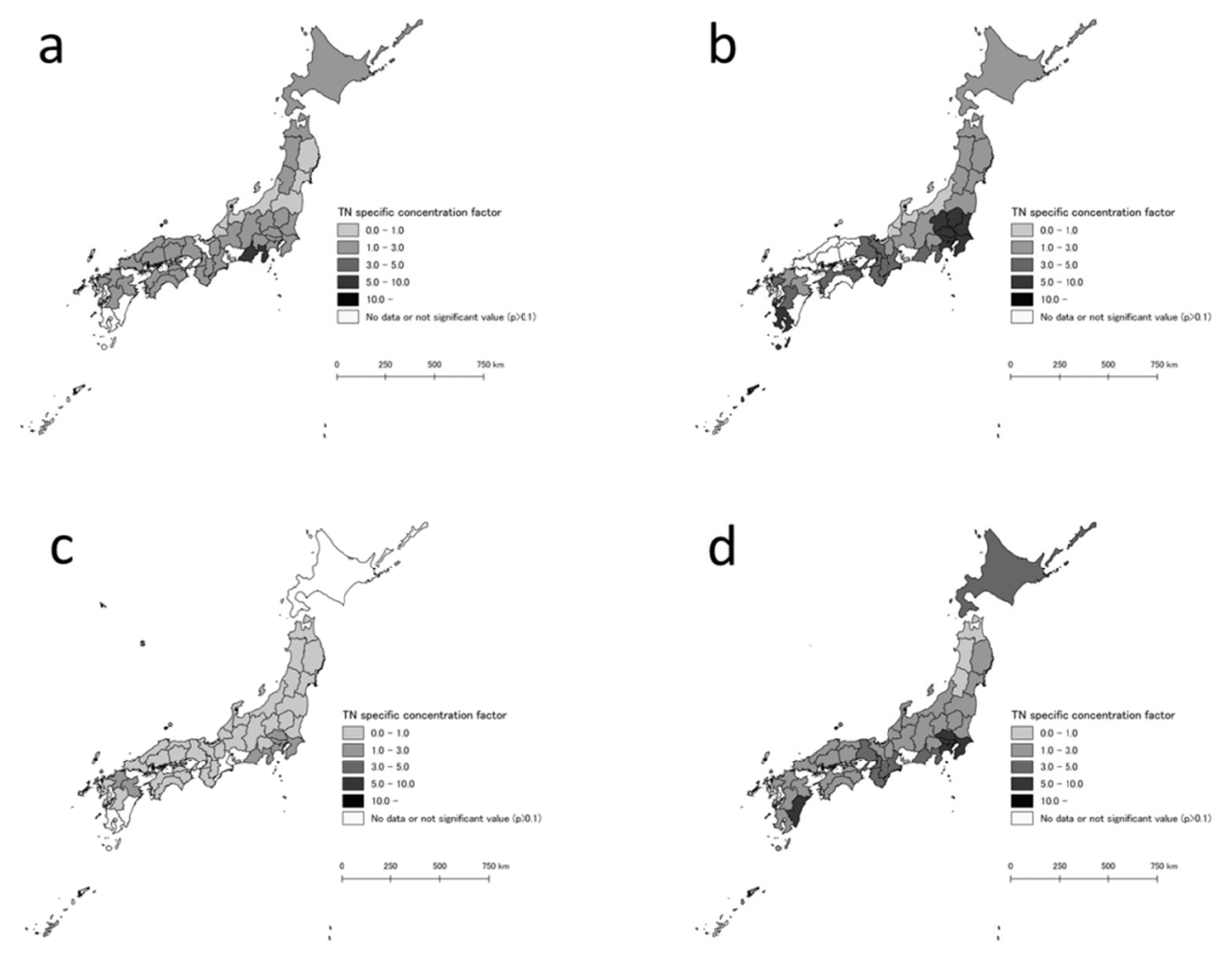

Figure 7. TN specific concentration factors for a:paddy fields, b:upland fields, c:forests, d; urban areas calculated by prefectures or regions. (Unconfident values ( $>0.1)$ are not described.) 
The surplus $\mathrm{N}$ of paddy and upland fields for each prefecture (Mishima et al. 2009, 2010) is presented in Fig. 8. Prefectural population density is shown in Fig. 9. The relationship between TN specific concentration factors and the surplus N, and the population density is depicted in Fig. 10. The TN specific concentration factors for paddy (Fig. 7a) and upland fields (Fig. 7b) were only loosely correlated to the surplus N (Figs. 8a, 8b) as shown in Figs. 10a and 10b. The TN specific concentration factor for forests (Fig. 7c) and urban areas (Fig. 7d) exhibited a positive relationship between the population density of each prefecture Fig. 9 as shown in Figs. 10c and 10d. The result for the TN specific concentration factors for forests tended to be large in high population density areas compared with low population density areas (Fig. 7c), which agrees with the findings of Itoh (2004), who interpreted the reason to be the deposition of nitrogen compounds from urban areas.
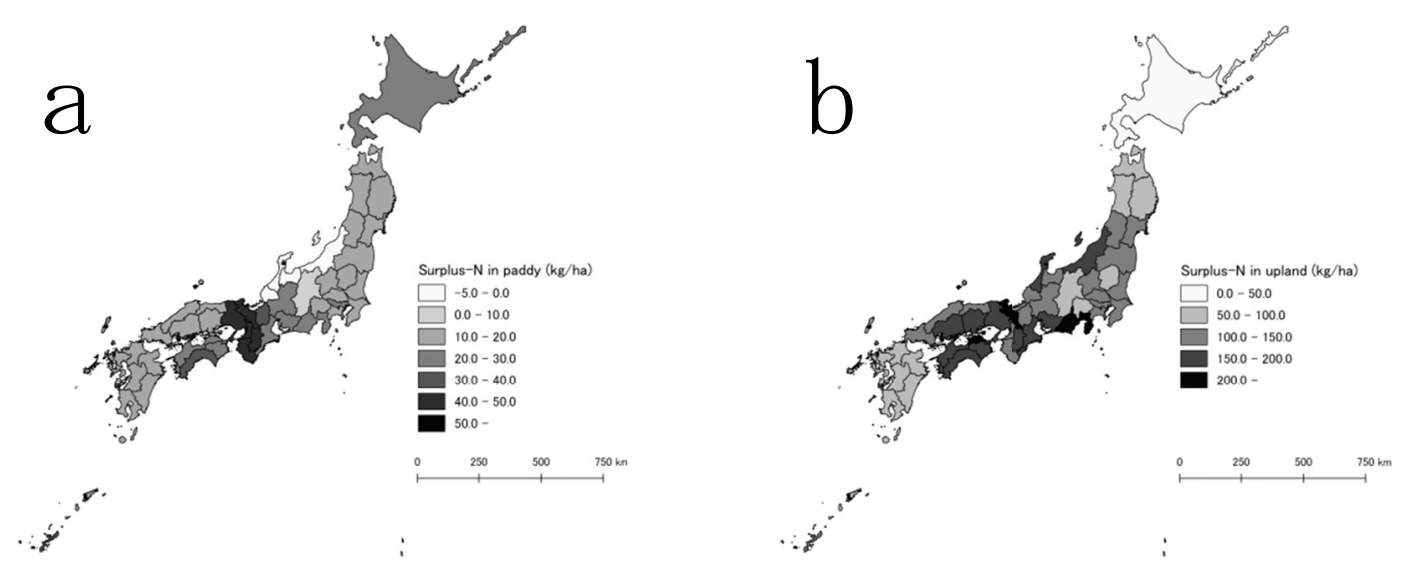

Figure 8. Distribution of calculated Surplus-N in a:paddy fields, b:upland fields

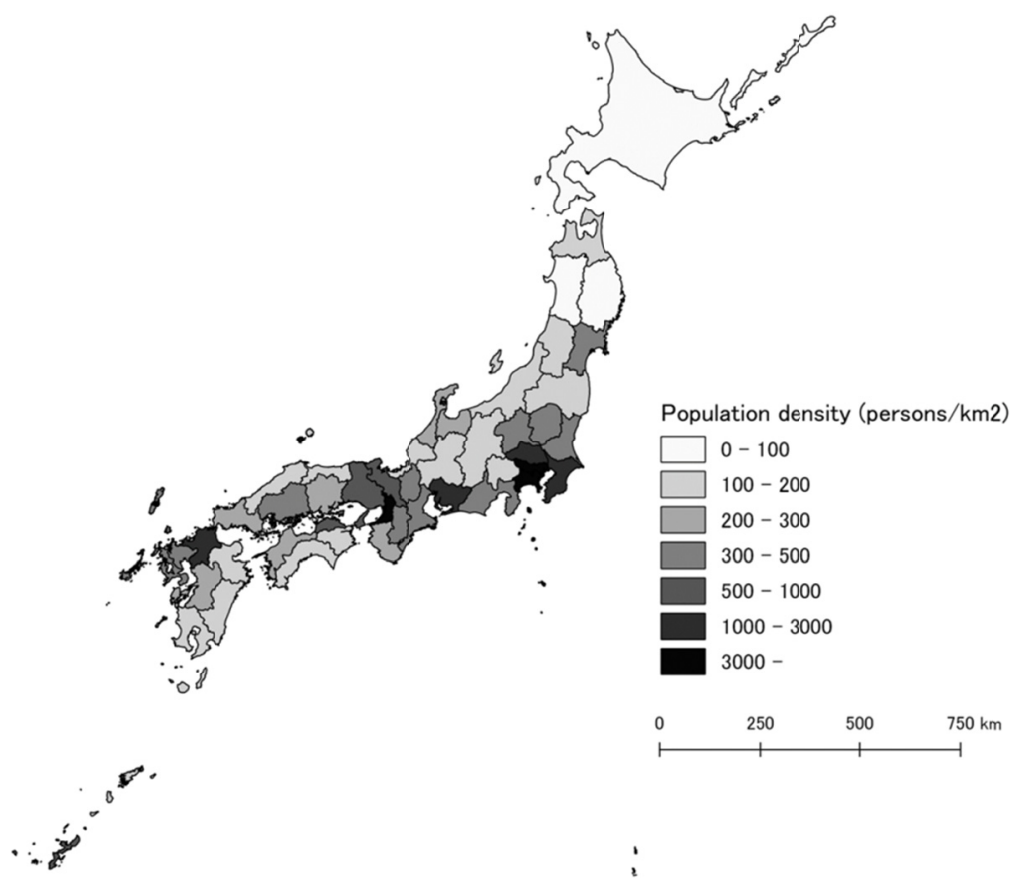

Figure 9. Population density by prefectures (2005) 
a
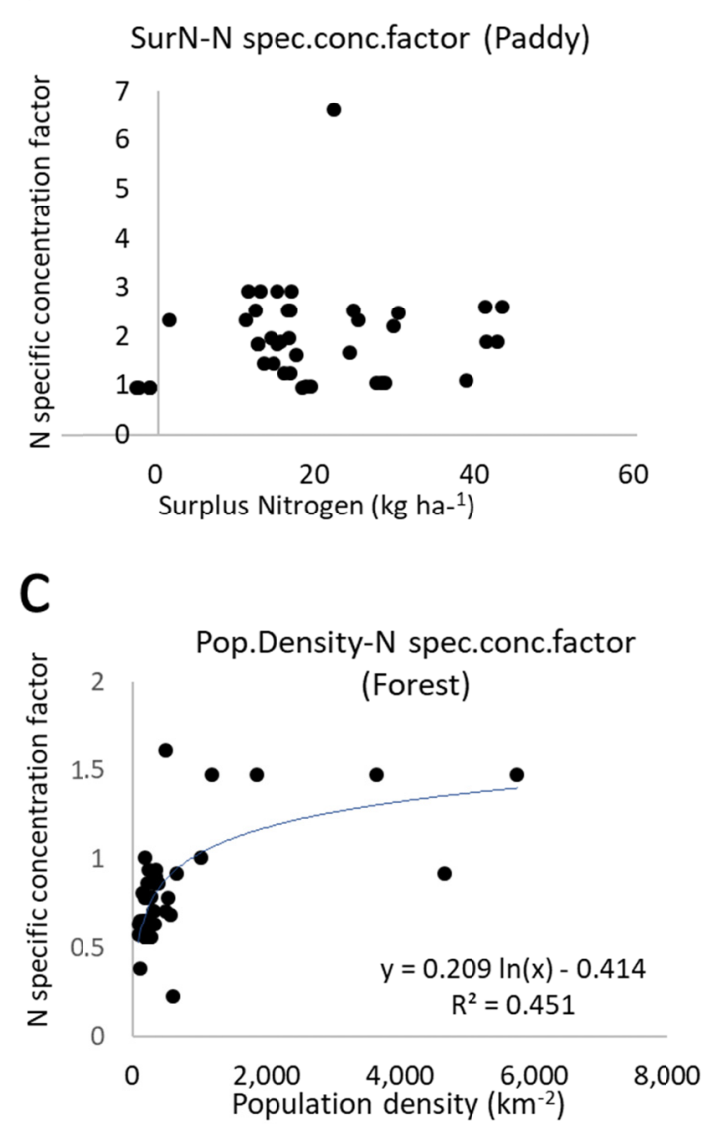

b
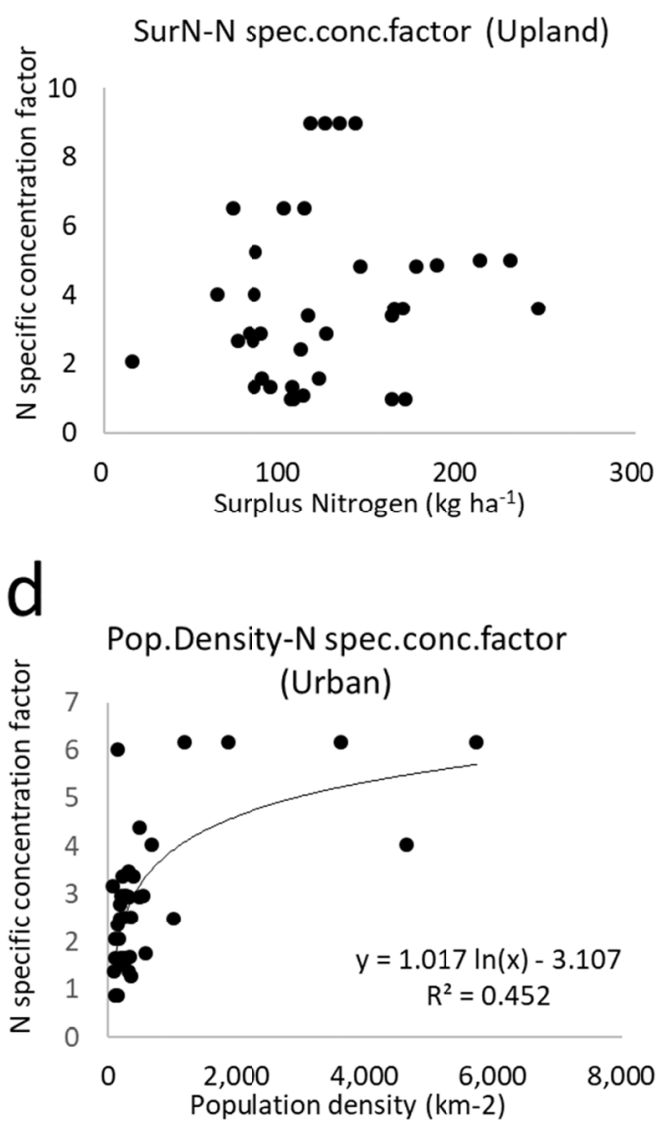

Figure 10. Relationship between N specific concentration factors and other factors

a: Relationship between surplus-N and TN specific concentration factors for paddy fields.

$\mathrm{b}$ : Relationship between surplus-N and TN specific concentration factors for upland fields.

c: Relationship between population density and TN specific concentration factors for forests.

$\mathrm{d}$ : Relationship between population density and TN specific concentration factors for urban areas.

\subsection{TP Concentration Distribution and TP Specific Concentration Factors for Each Land-Use Type}

The TP concentrations at the ends of watersheds are shown in Fig. 11. The TP concentrations were relatively high in the large urban areas such as Tokyo and its suburbs, Osaka and its suburbs, and Fukuoka and its suburban areas, similar to the TN concentration distribution. The calculated TP specific concentration factors by prefecture are depicted in Fig. 12 for each land-use type. Unconfident values ( $>0.1)$ are not shown. There were 3,256 delineated watersheds with observation points that included TP data for all 10 years. The TP specific concentration factor was 0.146 (from a $95 \%$ lower limit value of 0.119 to a $95 \%$ upper limit value of 0.172 ), 0.172 ( 0.138 to 0.206$), 0.044$ ( 0.033 to 0.055$)$, and 0.267 (0.253 to 0.282 ) for paddy fields, upland fields, forests and urban areas, respectively.

The surplus $P$ of paddy and upland fields for each prefecture (Mishima et al. 2009, 2010) are shown in Fig. 13. The relationship between TP specific concentration factors and the surplus $\mathrm{P}$, and the population density is depicted in Fig. 14. The TP specific concentration factors for paddy (Fig. 12a) and upland fields (Fig. 12b) were only loosely correlated to the surplus P (Figs. 14a, 14b). The TP specific concentration factor for forests (Fig. 12c) and urban areas (Fig. 12d) exhibited a positive relationship between the population density of each prefecture (Figs. 14c, 14d). 


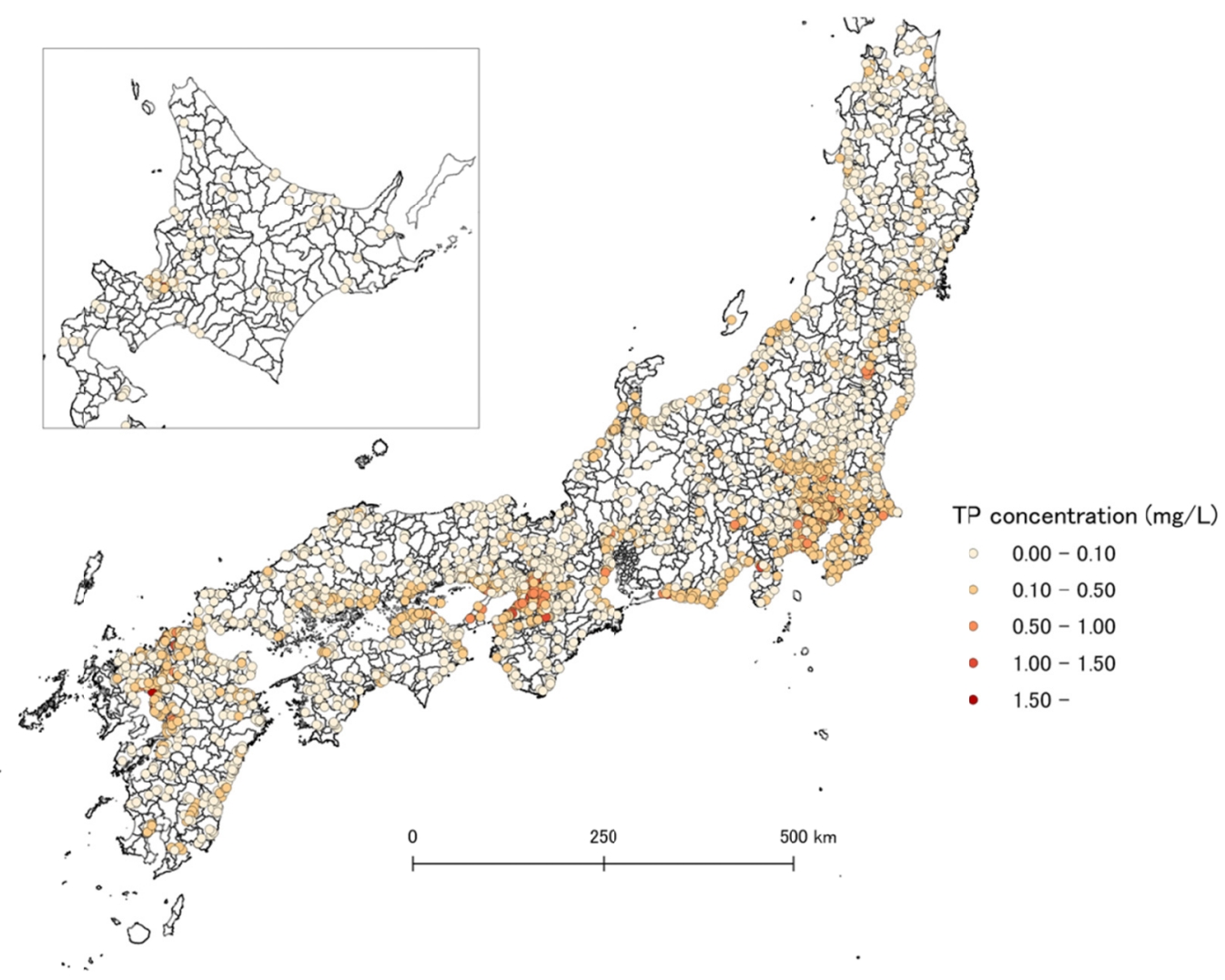

Figure 11. TP concentrations at the end of watersheds
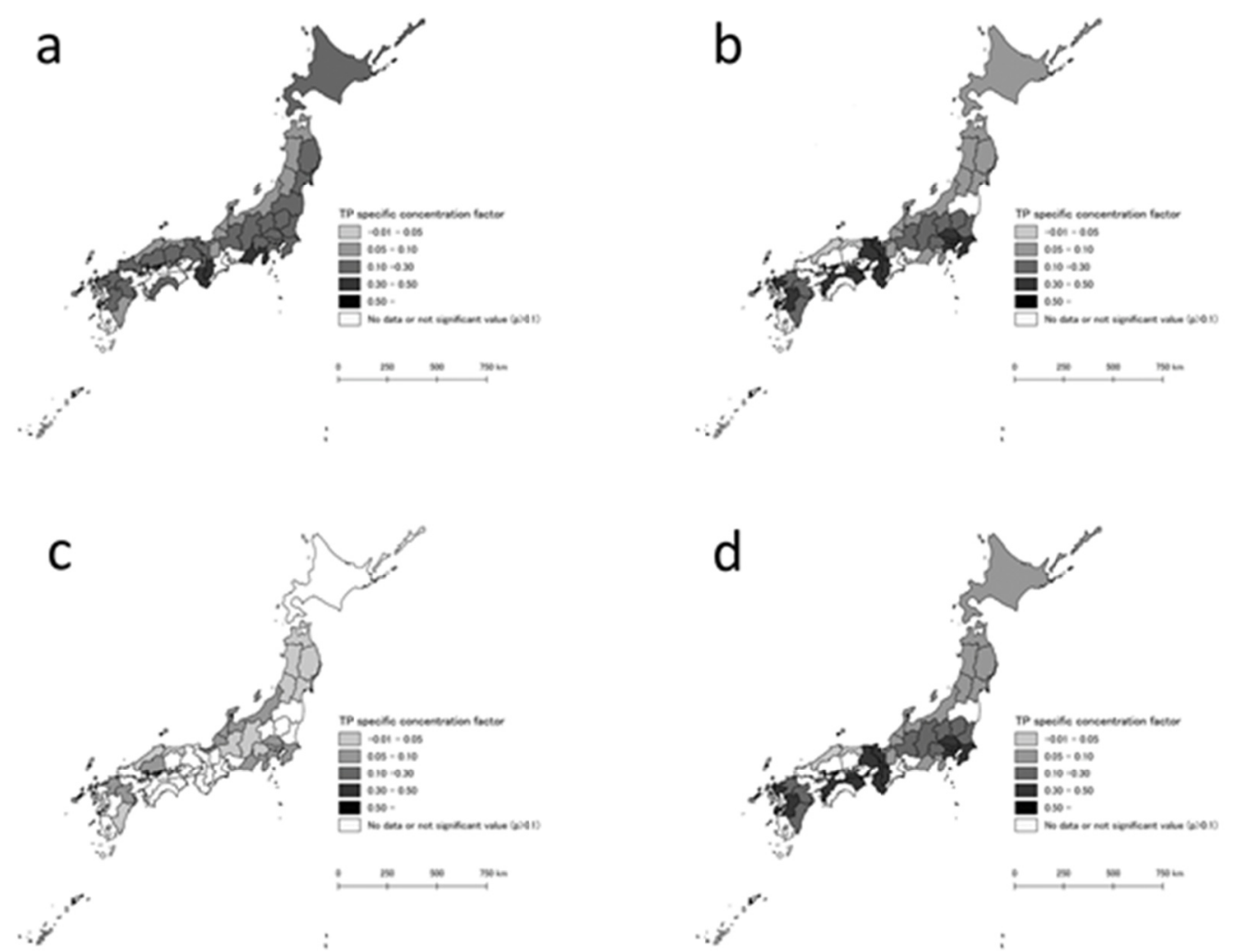

Figure 12. TP specific concentration factors for a:paddy fields, b:upland fields, c:forests, d; urban areas calculated by prefectures or regions. (Un confident values ( $>0.1)$ are not described.) 
a

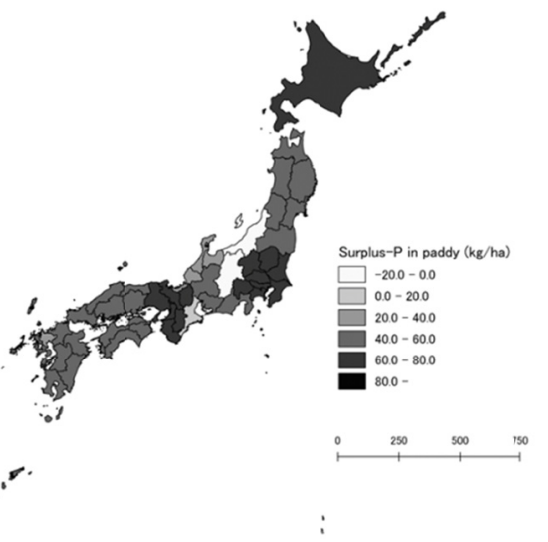

b

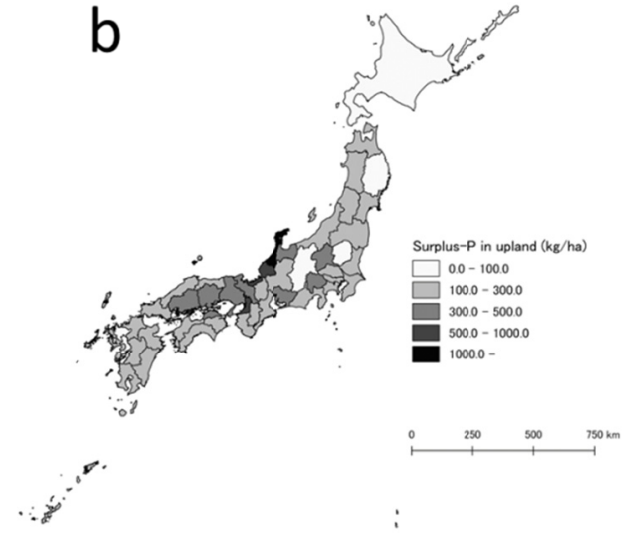

Figure 13. Distribution of calculated Surplus-P in a:paddy fields, b:upland fields

a

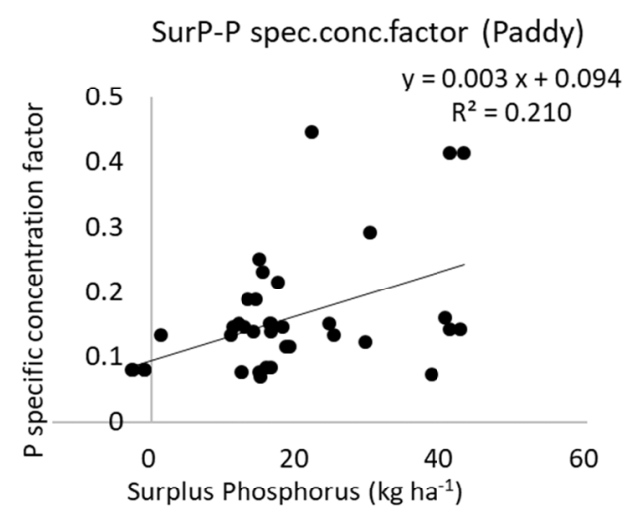

C

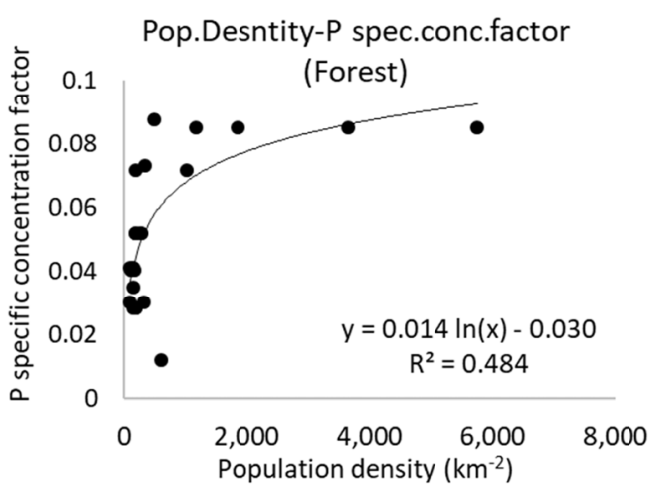

$\mathrm{b}$

SurP-P spec.conc.factor (Upland)

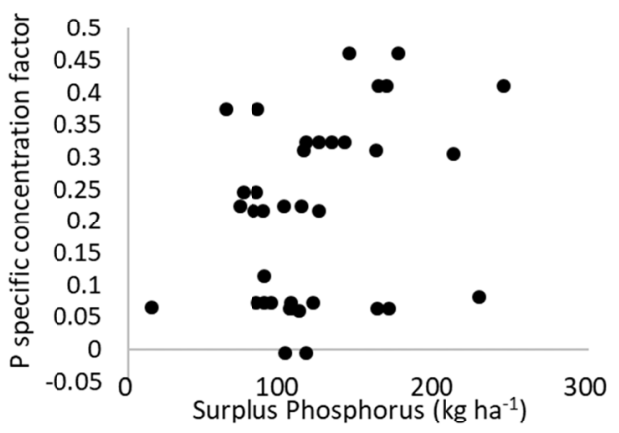

d

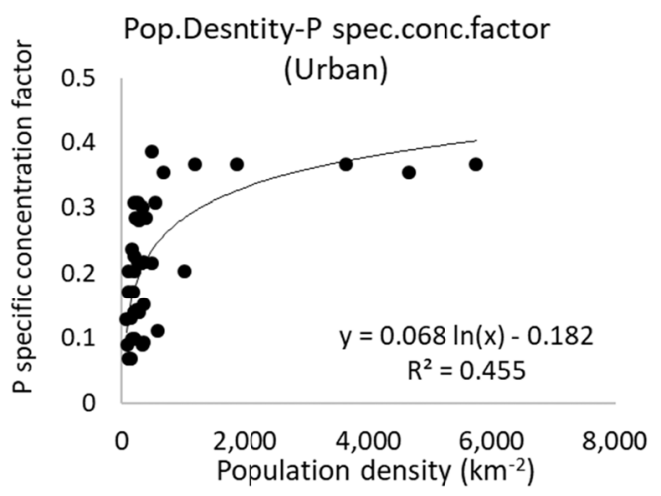

Figure 14. Relationship between TP specific concentration factors and other factors

a: Relationship between surplus-P and TP specific concentration factors for paddy fields.

b: Relationship between surplus-P and TP specific concentration factors for upland fields.

c: Relationship between population density and TP specific concentration factors for forests.

d: Relationship between population density and TP specific concentration factors for urban areas.

The results revealed that the TP specific concentration factors for forests tended to be large in suburban areas in comparison with local areas, similar to the results for TN. 


\section{Discussion}

There are many studies of the relationship between applied nitrogen on croplands and nitrogen concentrations in discharged water or river water (Hojito et al. 2003; Woli et al. 2002, 2004). Other studies have shown that increased livestock densities in a basin were associated with an increase in river nitrate concentrations (Shimura and Tabuchi 1997; Cheng et al. 2007). However, we were not able to find national-level water quality studies that include pollution loads from forests and urban areas.

The specific concentration factors calculated using equation (1) are the "net value", which is synonymous with "discharge minus inflow". In paddy fields, the inflow from irrigation water should not be neglected. Therefore, the negative values of the specific concentration factors indicate "purification" type. In general, $\mathrm{N}$ specific concentration factors for urban and upland areas were larger than those for paddy fields and forests, and $\mathrm{P}$ specific concentration factors for urban areas were larger than those for paddy fields and upland areas, and much larger than for forests. We proposed a simple method for determining the specific concentration factors for different land-use types in this and a previous paper (Mochizuki et al. 2013; Yoshikawa et al. 2015). The model has a simple framework and does not require special data. The model proposed here requires at least the same number of watersheds as the number of land-use types, and its applicability could be improved in situations where the loads from point sources are not large. Strictly speaking, SS, TN and TP pollution loads discharged into rivers contain not only loads from non-point sources but also loads from point sources. However, discharge from point sources such as factories and domestic discharge from urban areas have been significantly purified in sewage treatment plants before being discharged directly into the sea (approximately $80 \%$ in 2005, MILT 2019; Takahashi et al. 2010), and discharge from the inadequate disposal of livestock waste has decreased following the law concerning the Appropriate Treatment and Promotion of Utilization of Livestock Manure, enacted in 1999. Thus, nearly all of the current SS, TN, and TP runoff into rivers might be regarded as originating from non-point sources. Therefore, the accuracy of the model has improved under such conditions. The model is considered to be useful in estimating the change in SS, TN and TP concentrations in river water that have resulted from land-use changes. Furthermore, by multiplying annual water flow rates to SS, TN and TP specific concentration factors, those pollution load units (net values) from non point sources $\left(\mathrm{kg} \mathrm{ha}^{-1}\right.$ year $\left.^{-1}\right)$ can be calculated for each land use (Yoshikawa et al. 2015). In the next stage of investigation, SS, TN and TP runoff changes with changes in rainfall amount and intensity will be estimated by using data of water flow rate, rainfall, soil physical properties and so on for each watershed.

\section{Conclusions}

The aim of this study was to calculate SS, TN, and TP specific concentration factors that indicate those load intensities to rivers from each land-use type using a simple watershed model to contribute to the prediction of rainfall-related disasters in the future. The results demonstrate that the ranking of SS, TN and TP specific concentration factors were upland fields $>$ urban or paddy fields $>$ forests; however, the factors exhibited regional tendency likely because of the degree of agricultural intensity (SS, TN and TP) or the deposition of N compounds from urban areas (for the TN factor of forests) and so on.

\section{Acknowledgements}

The authors wish to thank Professor Shin-ich Onodera for inspiring this research, and Dr. Yuta Shimizu for his advice on GIS procedures. The authors also wish to thank Dr. Shin-ichiro Mishima for providing the database on surplus N and surplus P. We acknowledge Geospatial Information Authority of Japan (GSI), Space Technology Directorate for providing DEM data and LULC data. The original measuring point data were collected by National Institute for Environmental Studies (NIES) of Japan. This study was financially supported by a Grant-in-Aid for Scientific Research (B) from Japan's Society for the Promotion of Science.

\section{References}

Cheng, H., Ouyang, W., Hao, F., Ren, X., \& Yang, S. (2007). The non-point source pollution in livestock-breeding areas of the Heihe River basin in Yellow River. Stoch Environ Res Risk Assess, 21, 213-221. https://doi.org/10.1007/s00477-006-0057-2

Cooper, C. M. (1993). Biological effects of agriculturally derived surface water pollutants on aquatic systems-a review. J Environ Qual, 22, 402-408. https://doi.org/10.2134/jeq1993.00472425002200030003x

David, M. B., Gentry, L. E., Kovacic, D. A., \& Smith, K. M. (1997). Nitrogen balance in and export form an $\begin{array}{llllll}\text { agricultural watershed. } J & \text { Environ } & \text { Qual, } & \text { 26, }\end{array}$ https://doi.org/10.2134/jeq1997.00472425002600040015x

Hojito, M., Ikeguchi, A., Kohyama, K., Shimada, K., Ogino, A., Mishima, S., \& Kaku, K. (2003). Estimation of 
nitrogen loading in Japanese Prefectures and scenario testing of abatement strategies, Jpn (in Japanese with English summary). J Soil Sci Plant Nutr., 74, 467-474.

Itoh, Y., Miura, S., Kato, M., \& Yoshinaga, S. (2004). Regional distribution of nitrate concentrations in the stream water of forested watersheds in the Kanto and Chubu districts (in Japanese with English summary). $J$ Jpn For Soc, 86, 275-278.

Japan Meteorological Agency. (2019). Changes in heavy rain and hot summer days in the past (extreme events) (in Japanese). Retrieved from http://www.data.jma.go.jp/cpdinfo/extreme/extreme_p.html

Kumazawa, K. (2002). Nitrogen fertilization and nitrate pollution in groundwater in Japan: Present status and measures for sustainable agriculture. Nutrient Cycling in Agroecosystems, 63,129-137. https://doi.org/10.1023/A:1021198721003

Ma, D., Yoshikawa, S., Osawa, Y., Saito, T., Kobayashi, M., \& Eguchi, S. (2019). Study on potential influence of runoff on observatory-based watershed in Japan. J. Sustain. Dev., 12(4), 19-27.

Ministry of Land, Instructure, Transport and Tourism (Urban and Regional Development Bureau, Sewerage Department). (2019). Retrieved from http://www.mlit.go.jp/crd/city/sewerage/data/fukyu.html

Mishima, S., \& Kohyama, K. (2010). The database and the methodologies to estimate recent trend of nitrogen(N) and phosphate (P) flows and residual $\mathrm{N}$ and $\mathrm{P}$ in Japanese national prefectural scales and examples their application (in Japanese with English summary). Bull Natl Inst. Agro-Environ Sci, 27, 117-139.

Mishima, S., Endo, A., \& Kohyama, K. (2009) Nitrogen and phosphate balance on crop production in Japan on national and prefectural scales. Nutr Cycl Agroecosyst, 87, 159-173. https://doi.org/10.1007/s10705-009-9324-1

Mochizuki, H., Takahashi, H., \& Yoshikawa, S. (2013). Development of prediction model for water quality in watersheds based on proportion of area by land use (in Japanese with English summary). People and Environm., 39(3), 2-8. https://doi.org/10.5793/kankyo.39.3_2

Nagumo, T., Woli, K. P., \& Hatano, R. (2004). Evaluating contributions of point and non-point sources of nitrogen pollution in stream water in a rural area of central Hokkaido. Soil Sci Plant Nutri, 50, 109-117. https://doi.org/10.1080/00380768.2004.10408458

Shimura, M., \& Tabuchi, T. (1997). The relation between cattle farming and nitrogen concentration in stream waters: Research on nitrogen outflow from high stocking density area (IV) (in Japanese with English summary). Trans Jap Soc Irrigation Drainage Reclamation Engineering, 189, 375-384.

Tabuchi, T., Yoshino, K., Shimura, M., Kuroda, S., Ishikawa, M., \& Yamaji, E. (1995). Relation between land use and nitrate concentration of outflow water from watersheds of agricultural and forest area (in Japanese with English Summary). Trans Jap Soc Irrigation Drainage Reclamation Engineering, 178, 129-135.

Takahashi, H., Yoshikawa, S., Takano, H., Sasada, Y., \& Ninomiya, S. (2010). Estimation of pollution load from the Okayama and Kagawa basins flowing into the Seto Inland Sea in light of their basin characteristics (in Japanese with English summary). Jpn Journ Limnology, 71, 269-284. https://doi.org/10.3739/rikusui.71.269

Tokyo Marine Nichido. (2013). Increasing trend of concentrated torrential rain and responding to flood damage (in Japanese). Tokio Marine Nichido risk consulting company, 26, 1-6. Retrieved from http://www.tokiorisk.co.jp/risk_info/up_file/201306171.pdf

Woli, K. P., Nagumo, T., Kuramochi, K., \& Hatano, R. (2004). Evaluating river water quality through land use analysis and $\mathrm{N}$ budget approaches in livestock farming areas. Sci Total Environm., 329, 61-74. https://doi.org/10.1016/j.scitotenv.2004.03.006

Yoshikawa, S., Takahashi, H., Sasada, Y., \& Mochizuki, H. (2015). Impact of land use on nitrogen concentration in groundwater and river water. Soil Sci Plant Nutri, 61, 898-909. https://doi.org/10.1080/00380768.2015.1104521

\section{Copyrights}

Copyright for this article is retained by the author(s), with first publication rights granted to the journal.

This is an open-access article distributed under the terms and conditions of the Creative Commons Attribution license (http://creativecommons.org/licenses/by/4.0/). 